\title{
The effect of productive SafetyNet program on wasting among under-five children in the rural community of South Gondar Zone, Northwest Ethiopia
}

\author{
Melaku Tadege Engidaw *D and Alemayehu Digssie Gebremariam
}

\begin{abstract}
Background: Undernutrition is a significant public health problem in a developing country like Ethiopia. Even if the cause of malnutrition is multifactorial, it is mainly related to socioeconomical, political, and health-related problems. All these problems will lead to more severe nutrient deficiencies among households without assets. The Productive SafetyNet program is implemented for beneficiaries in the rural community to prevent household assets depletion. So, this study aimed to assess the effect of a Productive SafetyNet program on wasting among under-five children in the rural community of South Gondar Zone.
\end{abstract}

Methods: A community-based cross-sectional study was done among 803 children paired with their mother/caregivers. Particepnts were selected by a simple random sampling technique. The data were collected by using a structured and pretested questionnaire. AnthroPlus software was used to analyse anthropometric data. The data entry employed by Epilnfo version 7.0 software for Windows. Then, the data exported to SPSS version 20.0 to carryout further statistical analysis. The anthropometric index (weight for height) was constructed to determine wasting. Both binary and multivariable logistic regression models were used to identify associated factors. Finally, P-Value $\leq 0.05$ was used to declare statistical significance.

Results: In this study, the response rate was 95.76\%. Of the total participants, 195(25.36\%) children were from SafetyNet program beneficiaries. The overall prevalence of wasting was $29.9 \%$ (95\% Cl: 26.6, 33.2\%). More than One-fourth of the children from SafetyNet beneficiary households were wasted. While considering all other variables constant, Productive SafetyNet Program reduce wasting by $46 \%(C O R=0.54 .95 \% \mathrm{Cl}(0.37,0.79))$. Wasting were significantly associated with marital status (divorced and/or separated: $\mathrm{AOR}=3.33,95 \% \mathrm{Cl}(1.71,6.45)$ ), being on the SafetyNet program (AOR: 0.63, 95\% $\mathrm{Cl}(0.40,0.99))$, family size $(\mathrm{AOR}=0.13,95 \% \mathrm{Cl}(0.09,0.21))$, father educational status ( $\mathrm{AOR}: 0.25,95 \% \mathrm{Cl}(0.09,0.66))$, age of the child $(\mathrm{AOR}=0.51,95 \% \mathrm{Cl}(0.33,0.77))$, and child dietary diversity score $(\mathrm{AOR}=2.99,95 \% \mathrm{Cl}(1.67,5.35))$.

Conclusion: Wasting was a severe public health problem. In this study, the Productive SafetyNet Program reduce wasting significantly. Marital status, SafetyNet program status, family size, father educational status, age of the child, and dietary diversity were factors associated with wasting among children. Early detection of household asset depletion and SafetyNet program implementation is vital with the usual nutritional assessment and counseling.

Keywords: Productive SafetyNet program, Wasting, Associated factors, Under-five children, Ethiopia

\footnotetext{
* Correspondence: meltad24@gmail.com

Public Health Department, College of Health Sciences, Debre Tabor

University, P.o.Box: 031, Debre Tabor, Ethiopia
}

C C The Author(s). 2020 Open Access This article is licensed under a Creative Commons Attribution 4.0 International License, which permits use, sharing, adaptation, distribution and reproduction in any medium or format, as long as you give appropriate credit to the original author(s) and the source, provide a link to the Creative Commons licence, and indicate if changes were made. The images or other third party material in this article are included in the article's Creative Commons licence, unless indicated otherwise in a credit line to the material. If material is not included in the article's Creative Commons licence and your intended use is not permitted by statutory regulation or exceeds the permitted use, you will need to obtain permission directly from the copyright holder. To view a copy of this licence, visit http://creativecommons.org/licenses/by/4.0/ The Creative Commons Public Domain Dedication waiver (http://creativecommons.org/publicdomain/zero/1.0/) applies to the data made available in this article, unless otherwise stated in a credit line to the data. 


\section{Background}

The nutritional status of children is an indicator of economic growth, a reflection of the household's living standard, and child survival according to Millennium Development Goal one [1]. Even if Ethiopia has the highest population growth, currently, parallel economic growth, expansion of the services, and the agricultural sector's productivity play a vital role to reduce poverty [2]. With this economic growth, poverty, and food insecurity are still the main problem due to ineffective \& inefficient agricultural marketing system, underdeveloped transport, communications, and production technologies, limited access to rural households to support services, and environmental degradation which affects their livelihoods [3, 4].

Since 2005, the Productive SafetyNet program (PSNP) was implemented in Ethiopia as a new approach to address chronic food security through transfers to chronically food-insecure households to prevent asset depletion. In 2009, PSNP+ was launched to connect and enhance small income-generating activities by households through financial services and markets to have a selfsustainable finance [5-7]. Millions have enrolled into PSNP to meet consumer needs, reducing the risks they faced and providing them with alternative options to selling productive assets because of food insecurity [5].

Still today, household food insecurity, hunger, and undernutrition remain critical issues and persistent problems in Ethiopia. Also, undernutrition (like Wasting, Stunting, Underweight, and anaemia) is a public health significant problem in each region [8-11]. Amhara regional state is the one with the highest-burden of undernutrition, especially with the highest prevalence of poor nutritional status of women and children [12, 13]. Mainly, inadequate dietary intake, lack of dietary diversity, lack of nutrient density in the food, inappropriate feeding practices, and lack of hygienic practices are the cause of poor nutritional status among children. In addition to these, illness leads to failure to take and absorb adequate essential nutrients for their growth \& development [14].

There is a high prevalence of stunting, underweight, and wasting among children with PSNP dependent households as compared to those households without PSNP in Ethiopia [13]. Food insecurity leads to the poor nutritional status of children and decreasing productivity. This may follow the intergenerational life cycle and affects both the economic growth and development of the country at large. Food insecurity affects the school's attendance and educational attainment of adolescents in Southwest Ethiopia [15].

Even if undernutrition is a public health problem in Ethiopia, in this research, we are interested to assess the effect of the PSNP on wasting. The aim of the PSNP's in Ethiopia was to increase the percentage of children age 6 to 23 months to have access to minimum acceptable diet groups, household dietary diversity, the average value of asset holdings, and the number of different income sources. All these indicators show that PSNP has a positive effect on the current intake and avoid the risk of food insecurity [16]. The objective of the current study is to assess the effect of the PSNP on wasting among under-five children in the rural community of South Gondar Zone.

\section{Materials and methods}

\section{Study design and period}

A community-based cross-sectional study was employed from December 01 to January 30, 2017.

\section{Study area}

The study was conducted in the selected Woredas of South Gondar Zone. There are five Woredas/districts with a PSNP (LiboKemkem, Simada, Lay Gayint, Tach Gayint, and Ebnat) in South Gondar Zone. Among these, Simada and LiboKemekm Woreda were selected by lottery methods. In these districts, agricultural activities were limited to a single rainy season (from June to September). Maize, barley, and millet are the main food crops. Also, white rice, vetch, and chickpeas are the main cash crops. The number of households in the Woredas with a PSNP was more than 9000 (to public work and direct supports). The total number of children less than 5 years was 34,986. Among these, near to 20,000 (459 were selected) and 15, 000 (344 were selected) children were from Libo - Kemkem and Simada Woredas respectively.

\section{Eligibility criteria}

All rural children from 06 to 59 months of age with their caregiver/parents in Libo - Kemkem and Simada Woreda's during data collection periods were a part of this study. But, guest children and did not stay $>6$ months in the area were excluded.

\section{Sample size determination}

A single population proportion formula used to determine the sample size by taking a confidence level of $95 \%$, the marginal error of $5 \%$, and the prevalence of wasting was $38.7 \%$ from a study conducted in Wondogent, Sidama Zone, Ethiopia [17]. The final sample size was 803 children paired with their mother or caregivers after adding a design effect of 2 and $10 \%$ non-response rate.

\section{Sampling procedure}

A multistage sampling method was employed to select all the study participants from Libo - Kemkem and Simada Woredas. In Libo - Kemkem Woreda there were near to 20,000 children, 459 were included in this study and from Simada 344 children from near to 15, 000. Nine and eight Kebeles were selected from Libo- 
Kemekem and Simada Woreda respectively by using simple random sampling (random table) after listing all accessible rural kebeles alphabetically (A to Z).

Then, the proportional allocation of the sample size to each kebele was made. The required sample size of 0659 months was selected by using a simple random sampling technique after obtaining the list of each child in the family folder. During data collection, single children from 06 to 59 months were selected by lottery method from the household in case of two or more children within a single household were obtained.

\section{Measurements and tools for data collection}

Well-structured and pre-tested Amharic version questionnaires were used. The questionnaire had variables related to socio-economic, anthropometrical, maternal obstetric health, and dietary habits of the children. Except for anthropometrical data, all the others were collected from the mother/caregiver, including the dietary history (foods consumed by the child within the past $24 \mathrm{~h}$ ), socioeconomic, and maternal obstetric health-related variables.

The Anthropometric data were collected by using BSc Nurses. A total of 3 individuals per team was participated to collect the data. While one person records the data, the others took the height and weight. Here, standardization was done for each measurement. The child weight measured by using a calibrated electronic Seca scale (made in Germany). This device is accurate to $0.1 \mathrm{~kg}$. The child height measured three times with a Stadiometer, accurate to $0.1 \mathrm{~cm}$. Mid upper arm circumference (MUAC) was measured on the left arm for right-handed or vice versa by inserting arm circumference tape accurate to $0.1 \mathrm{~cm}$ using meter tape distributed by UNICEF for this purpose.

The weights were measured after take-off the shoes and wearing a possible light close. For children less than 2 years, we were using the panty bag to measure the weight. The wooden height or length board used to take the height $(>2 \mathrm{yrs})$ or the length $(<2 \mathrm{yrs})$ for children's interchangeably. The height/length was measured by placing the participants into the Frankfurt position.

\section{Data quality}

The questionnaire was prepared in the Amharic language to make it simple and easily understandable. Nine data collectors (a team of three individuals), three supervisors, and principal investigators were involved in the data collection process after 02 days training on how the data collectors and supervisors interview the mothers, fill the questionnaire, and taking physical measurements by using standard instruments of weighing scale and height/length board. The pre-test was done on 20 children from adjacent Woredas before actual data collection. After the pre-test, necessary correction and modification were done.
To get the appropriate age, we reduced recall bias by using prominent local events, Baptism cards, and immunization cards. Weighing scales were calibrated by using $1 \mathrm{~kg}$ of standard weight before each measurement. Three consecutive measurements were taken to ensure accuracy. Finally, the average score of the three measurements used to determine the child's height and weight. Weight and length/height were recorded into the nearest $0.1 \mathrm{~kg}$ and $0.1 \mathrm{~cm}$ respectively. All collected questionnaires were reviewed every night by the supervisors and investigators to check completeness and consistency. Then, the feedback was given to the data collectors to handle the problems faced during data collection.

\section{Definitions of terms}

Wasting: when a child's weight for height Z-score was < $-2 \mathrm{SD}$ of the median value of the NCHS/WHO curve [18].

Underweight - when a child's weight for age Z-score was $<-2$ SD of the median value of the NCHS/WHO curve [18].

Household: People who sleep under the same roof and take meals together at least 4 days a week.

Households with PNSPs: households identified as chronically food insecure and currently under a cash transfer or asset-building program [19, 20].

Kebele: is the smallest administrative division or village in Ethiopia.

Dietary diversity score (DDS): is the consumed food by the child within $24 \mathrm{~h}$ and was categorized as low (consumed $<4$ food groups) and good (consumed $\geq 4$ food groups) dietary diversity scores [21].

\section{Data processing and analysis}

The age, sex, height/length, and weight of children entered into the WHO AnthroPlus software to build anthropometric indices based on the growth reference of NCHS to compute anthropometric indices. During WFH analysis, all flagged cases were excluded from this analysis. All the data entered by using EPI info version 7.0 and then exported into SPSS version 20.0 for windows for cleaning and analysis. Both bivariable and multivariable logistic regressions were done to identify the associated factors of wasting. Then, COR and AOR with 95\% CI were used to see the levels of significance of the association. Finally, $\mathrm{p}$ valve $\leq 0.05$ was used to declare statistical significance.

\section{Results}

\section{Socio-demographic characteristics}

The response rate for this study was $95.76 \%$. The average age \pm SD the respondent was $30.11 \pm 5.16$ years and the majority of the respondents $(267(34.7 \%))$ found between the ages of 25 to 29 years. All of them were Orthodox by religion. One-fourth of the households are under the SafetyNet program. More than $3 / 4$ of the mother and caregiver (591(76.9)) can read and write. The average age \pm SD the child was $31.30 \pm 20.51$ months and near to $55 \%$ found between 23 and 59 months of age' (Table 1 ). 
Table 1 Socio-economic characteristics of the respondent to the effect of PSNP on wasting among children 06-59 months of age in selected Woredas of South Gondar Zone Ethiopia, $2017(n=769)$

\begin{tabular}{|c|c|c|c|}
\hline Variable & Categories & Frequency & Percent \\
\hline \multirow[t]{7}{*}{ Current maternal age (completed years) } & $15-19$ & 12 & 1.6 \\
\hline & $20-24$ & 76 & 9.9 \\
\hline & $25-29$ & 267 & 34.7 \\
\hline & $30-34$ & 252 & 32.8 \\
\hline & $35-39$ & 107 & 13.9 \\
\hline & $40-44$ & 55 & 7.2 \\
\hline & $45-49$ & 09 & 1.2 \\
\hline \multirow[t]{2}{*}{ Household head } & Husband/brother ${ }^{\mathrm{a}}$ & 734 & 95.4 \\
\hline & Wife/Sister $^{\mathrm{a}}$ & 35 & 4.6 \\
\hline \multirow[t]{2}{*}{ Enrolled in the PSNP } & Yes & 195 & 25.4 \\
\hline & No & 574 & 74.6 \\
\hline \multirow[t]{3}{*}{ Marital status } & Single & 59 & 7.7 \\
\hline & Married & 630 & 81.9 \\
\hline & Separated & 80 & 10.4 \\
\hline \multirow[t]{2}{*}{ Respondent's educational status } & unable to read and write & 591 & 76.9 \\
\hline & able to read and write & 178 & 23.1 \\
\hline \multirow[t]{3}{*}{ Husband's educational status } & unable to read and write & 427 & 55.5 \\
\hline & able to read and write & 314 & 40.8 \\
\hline & primary education and above & 28 & 3.7 \\
\hline \multirow[t]{3}{*}{ Respondent's occupation } & Housewife & 385 & 50.0 \\
\hline & Daily labourer & 35 & 4.6 \\
\hline & Farmer & 349 & 45.4 \\
\hline \multirow[t]{2}{*}{ Husband's occupation } & Daily labourer & 36 & 4.7 \\
\hline & Farmer & 733 & 95.3 \\
\hline
\end{tabular}

${ }^{a}$ this brother or sister is for orphanage children; these children caregivers will be married or not

\section{Obstetrics related characteristics}

The average age difference between the index and the next child \pm SD was $3.20 \pm 1.54$ years. The majority of the mothers and caregiver (592 (77.0\%)) started complementary feeding at the age of $\geq 06$ months. Near to $5 \%$ of the mother gives extra food/beverages after delivery instead of colostrum. Of all deliveries, $85 \%$ of the children delivered at health institutions (Table 2).

\section{The magnitude of wasting and dietary related characteristics}

The mean age $\pm \mathrm{SD}$ was $23.38 \pm 13.20$ months. The mean \pm SD of weight and height of the child was $10.05 \pm$ $2.54 \mathrm{Kg}$ and $81.12 \pm 14.49 \mathrm{~cm}$ respectively. The mean \pm SD of MUAC was $13.24 \pm 0.92 \mathrm{~cm}$. In this study, the number of children with a MUAC $\leq 11.5 \mathrm{~cm}$ was 06(0.78\%). The mean \pm SD of WFH z score was $-0.79 \pm$ 1.98. The prevalence of wasting was $29.9 \%$ (95\% CI: 26.6 , $33.2 \%$ ) and from this, $16.5 \%$ (95\% CI:13.8, 19.2\%) were very severe. Of the total participants, 195 (25.36\%) children were from SafetyNet program beneficiaries (Fig. 1).
The average dietary diversity score \pm SD was $5.23 \pm$ 1.14 by using a 24-h dietary recall. Most of the children $(678(88.2 \%))$ had a good dietary diversity score.

\section{Factors associated with wasting}

While all other factors were assumed constant, being a part of a PSNP household family member reduces the prevalence of wasting by $46 \%$ (COR: $0.54,95 \%$ CI $(0.37,0.79)$.

Also, the combined effects of the variables were assessed by bivariable and multivariable binary logistic regression models. In bivariate logistic regression; marital status, the age of the child, the sex of the child, family size, enrolled in the PSNP, father educational status, husband's occupation, maternal occupation, child's dietary diversity score (CDDS), history of ANC follow-up, birth interval, and vaccination history were the significant variables.

Finally, marital status, father educational status, being on PSNP, family size, age of the child, and child DDS were the associated factors for the development of 
Table 2 Obstetrics related characteristics of the respondent to the effect of PSNP on wasting among children 6-59 months of age in the selected Woredas of South Gondar Zone, Ethiopia, $2017(n=769)$

\begin{tabular}{|c|c|c|c|}
\hline Variable & Categories & Frequency & Percent \\
\hline \multirow[t]{2}{*}{ The age difference between the last two children } & $<2$ years & 283 & 36.8 \\
\hline & $\geq 2$ years & 486 & 63.2 \\
\hline \multirow[t]{2}{*}{ Breastfeeding status } & Yes & 744 & 96.7 \\
\hline & No & 25 & 3.3 \\
\hline \multirow[t]{3}{*}{ Age to start complementary feeding } & Immediately after birth & 59 & 7.7 \\
\hline & 01-06 months & 118 & 15.3 \\
\hline & $\geq 6$ months & 592 & 77.0 \\
\hline \multirow[t]{2}{*}{ Giving additional/other foods or beverages after delivery } & Yes & 37 & 4.8 \\
\hline & No & 732 & 95.2 \\
\hline \multirow[t]{2}{*}{ Bottle feeding } & Yes & 68 & 8.8 \\
\hline & No & 701 & 91.2 \\
\hline \multirow[t]{2}{*}{ Attending ANC for current child } & Yes & 697 & 90.6 \\
\hline & No & 72 & 9.4 \\
\hline \multirow[t]{2}{*}{ Place of delivery } & Health institution & 654 & 85.0 \\
\hline & Home & 115 & 15.0 \\
\hline \multirow[t]{2}{*}{ Vaccination history } & Yes & 720 & 93.6 \\
\hline & No & 49 & 6.4 \\
\hline \multirow[t]{2}{*}{ Illness in the last 2 weeks } & Yes & 193 & 25.1 \\
\hline & No & 576 & 74.9 \\
\hline \multirow[t]{2}{*}{ Hand washing practice } & Yes & 656 & 85.3 \\
\hline & No & 153 & 14.7 \\
\hline
\end{tabular}

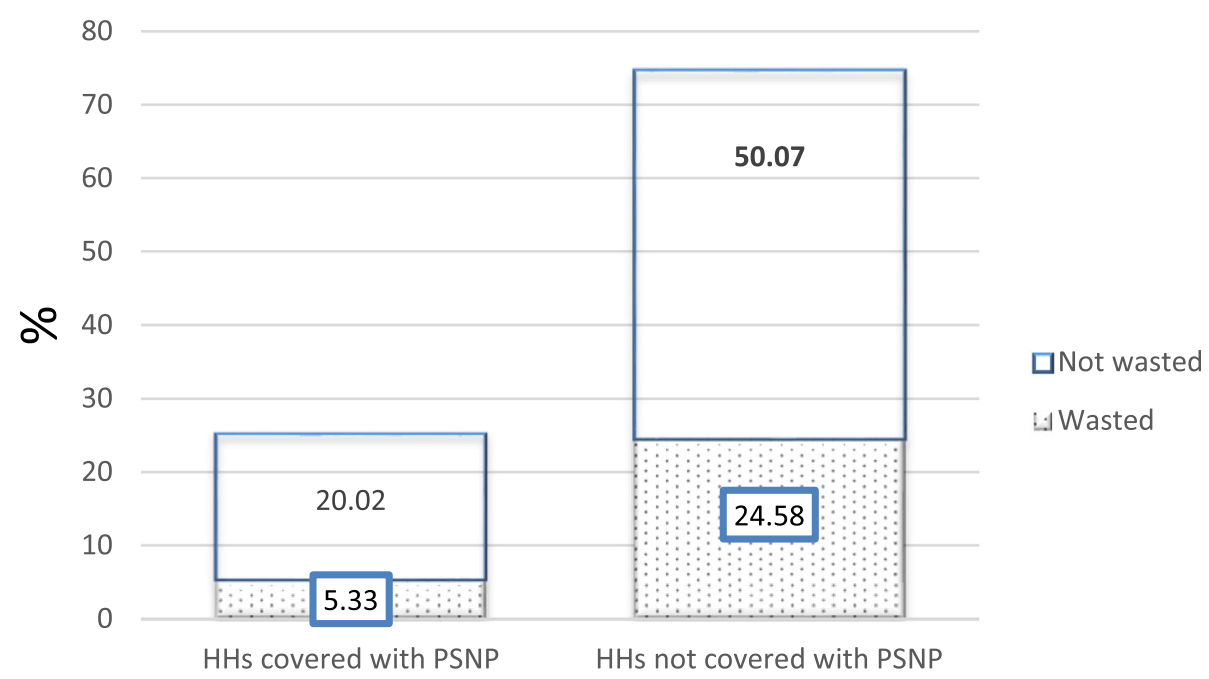

HHs status in relation toPSNP

Fig. 1 The percentage of wasting from households covered and not covered with PSNP among 06-59 months of age children in the selected Woredas of South Gondar Zone, Ethiopia, $2017(n=769)$ 
wasting among children aged 6-59 months during multivariable binary logistic regression (Table 3 ).

Children from divorced and separated women were 3.3 times (AOR: 3.33, 95\% CI $(1.71,6.45))$ more likely to develop wasting as compared to married. Children aged 24-59 months were $49 \%$ (AOR: $0.51,95 \%$ CI $(0.33,0.77)$ ) less likely to develop wasting as compared to $12-23$ months of age. Also, children from smaller family sizes were $87 \%$ (AOR: $0.13,95 \% \mathrm{CI}(0.09,0.21))$ less likely to develop wasting.

Children who had a father above the primary educational level were $75 \%$ (AOR: $0.25,95 \%$ CI $(0.09,0.66)$ ) less likely to be wasted as compared to unable to read and write. Children from households enrolled with PNSP were 37\% (AOR: 0.63, 95\% CI $(0.40,0.99)$ ) less likely to develop wasting as compared to families not covered with PSNP. In addition to this, children with low DDS were 3 times (AOR: 2.99, 95\% CI $(1.67,5.35)$ ) more likely to develop wasting.

\section{Discussion}

In Ethiopia, still, undernutrition is a significant public health problem. Personal and community-level factors were significant determinants of childhood under-nutrition $[8$, 22]. In this study, the overall prevalence of wasting was $29.9 \%$ (95\% CI: 26.6, 33.2\%). Here, the prevalence of wasting is higher than the national prevalence reported by EDHS 2016 (10\%) [8]. On the other hand, the finding is low as compared to the studies conducted at Wondogenet District, Sidama Zone, Southern Ethiopia (15.7\%) [17] but comparable to the study conducted at Jigiga Town, Somalia Regional State, Ethiopia [23]. The possible reasons might be the difference in the data collection period, socioeconomic status of parents, cultural difference, knowledge related to child feeding, and dietary habit.

Here, being in PSNP alone reduce the rate of wasting by 46\%. In Ethiopia, enrolment into PSNP is based on household assets or wealth depletion; the program is designed for the poor to halt this problem. Those children from households with good assets or wealth were less likely to be wasted. These households might not have the risk of food self-sufficiency or acute shortage of foods. So, building household assets are very important by expanding this PSNP since socioeconomic status is one of the important prognosticators of an individual's health status [24, 25]. Generally, the wealth status and possession score are used to assess household assets depletion based on the ownership status of selected household items [26, 27].

As a result, children from households enrolled with PSNP were 37\% (AOR: 0.63, 95\% CI $(0.40,0.99)$ ) less likely to develop wasting as compared to families without PSNP which is similar to other studies conducted in Bangladesh and Cote d'Ivoire [27, 28]. This may be due to the strong relationship between low socioeconomic status and nutritional status. So, those households with
PSNP were eligible due to the depleted household asset and/or poor agriculture productivity.

Children from divorced and separated women were 3.33 times (AOR: $3.33,95 \%$ CI $(1.71,6.45)$ ) more likely to develop wasting as compared to married women. This finding is in line with a study conducted in Dabat Town, North Gondar, Ethiopia [29]. On the other hand, this finding differed from the study result from Nakaseke and Nakasongola District, Uganda; most of the wasted children were from mothers who were married [30]. The possible justification might be household assets will deplete after divorce and being a female-headed household is a risk for economic burden.

Children who had a father above the primary educational level were $75 \%$ (AOR: 0.25 , 95\% CI $(0.09,0.66)$ ) less likely to be wasted as compared to unable to read and write. The finding is similar to the study conducted in Jigjiga Town, Somali Regional State, Ethiopia [23]. The possible reason might be educational status associated with good feeding practice, better income, and asset building.

Children aged 24-59 months were 49\% (AOR: 0.51, 95\% CI $(0.33,0.77))$ less likely to develop wasting as compared to $12-23$ months of age. This is comparable with the national demographic and health survey of Ethiopia and a study conducted in Wondogenet District, Sidama Zone, Southern Ethiopia $[8,17]$. Because, as the age increases the nutritional requirement increases, reduction of child care, discontinuation of breastfeeding, being pregnant of the mother, and poor dietary practice.

The other factor significantly associated with wasting was the family size. Children from smaller family sizes were $87 \%$ (AOR: $0.13,95 \%$ CI $(0.09, .21)$ ) less likely to develop wasting like a study conducted in Jimma Zone, Southwest, Ethiopia [31] and Sebeta, Hawas District, Oromia, Ethiopia [32]. The possible reasons may be due to large family size with low socioeconomic status, which leads to inadequate intake, monotonous diet, a diet with poor nutrient density, inappropriate feeding practices, lack of hygienic practices, and illness. All these will lead to failure to take and absorb essential nutrients for growth \& development [14] and may be due to household asset depletion.

In addition to this, children with low DDS were 3 times (AOR: $2.99,95 \%$ CI $(1.67,5.35)$ ) more likely to develop wasting. The dietary habit is the major factor, according to the systematic review and meta-analysis was done in Ethiopia [33]. The dietary habit, practice, and density highly, influenced by the socio-economic status of households which directly affect the nutritional status of the child.

The study was limited to link wasting to specific macronutrient deficiency, difficult to establish a possible causality, and recall-related problems (like a child date of birth and history of dietary intake). In addition to this, the study did not include clinical assessment and did not detect the subclinical condition. 
Table 3 Factors associated with wasting among children aged 06-59 months in selected Woredas of South Gondar Zone Ethiopia, $2017(n=769)$

\begin{tabular}{|c|c|c|c|c|}
\hline \multirow[t]{2}{*}{ Variable } & \multicolumn{2}{|c|}{ Wasting } & \multirow[t]{2}{*}{ COR $(95 \% \mathrm{CI})$} & \multirow[t]{2}{*}{ AOR $(95 \% \mathrm{Cl})$} \\
\hline & Yes & No & & \\
\hline \multicolumn{5}{|l|}{ Marital status } \\
\hline Married & 186 & 444 & 1 & 1 \\
\hline Single & 7 & 52 & $0.32(0.14,0.72)$ & $0.63(0.25,1.56)$ \\
\hline Divorced and separated & 37 & 43 & $2.05(1.28,3.29)$ & $3.33(1.71,6.45)^{a}$ \\
\hline \multicolumn{5}{|l|}{ Age of the child } \\
\hline 6-11 months & 44 & 982 & $0.72(0.47,1.09)$ & $0.80(0.49,1.30)$ \\
\hline $12-23$ months & 60 & 40 & $0.39(0.28,0.57)$ & $0.51(0.33,0.77)^{a}$ \\
\hline 24-59 months & 126 & 201 & 1 & 1 \\
\hline \multicolumn{5}{|l|}{ Sex of the child } \\
\hline Female & 127 & 247 & $1.46(1.07,1.99)$ & $1.18(0.82,1.70)$ \\
\hline Male & 103 & 292 & 1 & 1 \\
\hline \multicolumn{5}{|l|}{ Family size (mean) } \\
\hline$\leq 4$ & 182 & 205 & 1 & 1 \\
\hline$>4$ & 48 & 334 & $0.16(0.11,0.23)$ & $0.13(0.09,0.21)^{a}$ \\
\hline \multicolumn{5}{|l|}{ enrolled in the PSNP } \\
\hline Yes & 41 & 154 & $0.54(0.37,0.79)$ & $0.63(0.40,0.99)^{a}$ \\
\hline No & 189 & 385 & 1 & 1 \\
\hline \multicolumn{5}{|l|}{ Father educational status } \\
\hline Unable to read \& write & 140 & 287 & $0.56(0.26,1.21)$ & $0.25(0.09,0.66)$ \\
\hline Able to read and write & 77 & 237 & $0.38(0.17,0.82)$ & $0.14(0.05,0.37)$ \\
\hline Above primary education & 13 & 15 & 1 & 1 \\
\hline \multicolumn{5}{|l|}{ Husband occupation } \\
\hline Farmer & 7 & 29 & 1 & 1 \\
\hline Daily labourer & 233 & 510 & $1.81(0.78,4.20)$ & $1.39(0.45,4.26)$ \\
\hline \multicolumn{5}{|l|}{ Maternal occupation } \\
\hline Housewife & 129 & 256 & $1.49(1.08,2.06)$ & $1.43(0.97,2.10)$ \\
\hline Daily labourer & 13 & 22 & $1.75(0.85,3.63)$ & $2.33(0.90,6.02)$ \\
\hline Farmer & 88 & 261 & 1 & 1 \\
\hline \multicolumn{5}{|l|}{ CDDS } \\
\hline Poor (> 4 food groups) & 39 & 52 & $1.91(1.22,2.99)$ & $2.99(1.67,5.35)^{a}$ \\
\hline Good ( $\geq 4$ food groups) & 191 & 487 & 1 & 1 \\
\hline \multicolumn{5}{|l|}{ History of ANC follow-up } \\
\hline Yes & 201 & 496 & 1 & 1 \\
\hline No & 29 & 43 & $1.66(1.01,2.74)$ & $1.29(0.68,2.48)$ \\
\hline \multicolumn{5}{|l|}{ Birth interval } \\
\hline$<2$ years & 62 & 221 & $0.53(.38,0.75)$ & $0.79(0.53,1.19)$ \\
\hline$\geq 2$ years & 168 & 318 & 1 & 1 \\
\hline \multicolumn{5}{|l|}{ Vaccinated } \\
\hline Yes & 224 & 496 & 1 & 1 \\
\hline No & 6 & 43 & $0.31(0.13,0.74)$ & $0.43(0.16,1.18)$ \\
\hline
\end{tabular}

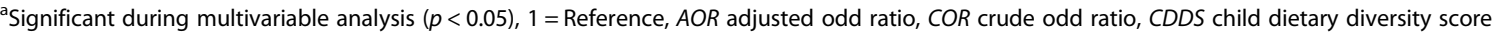




\section{Conclusions}

Generally, wasting was a severe public health problem. Being in the PSNP families had a significant contribution to the reduction of wasting or thinness among children independently. Generally, factors associated with wasting were marital status, being on the PSNP family, family size, the age of the child, and child DDS after adjusting/ running all other variables.

Based on the finding, stakeholders should have to continue and expand the PSNP with the existed nutrition and other health-related strategies/programs to tackle wasting. Also, health professionals shall have to give health and nutrition education and counselling based on the age of the child, maternal educational status, and households PSNP enrolment status through other child and reproductive health care services.

\section{Abbreviations \\ AOR: Adjusted odds ratio; BMl: Body mass index; COR: Crude odds ratio; DDS: Dietary diversity score; HEWs: Health extension workers; \\ PSNP: Productive safetynet program; SD: Standard deviation; SPSS: Statistical packages for social sciences; WHZ: Weight for height Z score; WAZ: Weight for age Z score; WHO: World Health Organization}

\section{Acknowledgments}

We deeply acknowledge all the study participants, the staff of Woreda Health offices, Debre Tabor University, Supervisors, and data collectors for their cooperation and commitment during this study.

\section{Authors' contributions}

MTE: made the draft of the proposal, and acquisition, analysis of data, and on the interpretation or discussion, results of the manuscript. ADG: worked on the analysis, on the interpretation, discussion, results, and revise the manuscript. All the authors read and approved the final manuscript.

\section{Funding}

We did not receive any funds for this project except support from Debre Tabor University.

\section{Availability of data and materials}

All the important data found in the manuscript.

\section{Ethics approval and consent to participate}

Ethical clearance was obtained from the Institutional Review Board of Debre Tabor University, College of Health Sciences. An official letter was obtained from Zonal Health Department than to the respective Woreda. Oral consent was obtained from each study participant's mother or caregiver after they were included in this study. First, the purpose of the study was explained to them and we have assured tier privacy and confidentiality throughout the data collection and after. Lastly, they got information about the rights to interrupt and to refuse the interview process at any time. After analysing the data, we assured that the result of the study will be published in an international scientific journal. The weight and height of the children were measured as much as possible without posing discomfort. A child with poor nutritional status was referred to the nearby health center by using a referral slip of HEWs in addition to health education and advice.

\section{Consent for publication}

Not Applicable.

\section{Competing interests}

We declare that there is no competing interest with anyone else.
Received: 19 June 2020 Accepted: 6 October 2020

Published online: 12 October 2020

\section{References}

1. Horton R, Lo S. Nutrition: a quintessential sustainable development goal. Lancet. 2013;382(9890):371-2

2. World Bank, Ethiopia: Country Profile. 2015, World Bank.

3. IFAD. Rural poverty portal, rural poverty in Ethiopia, 2010 [Available from: http:// www.ruralpovertyportal.org/web/guest/country/home/tags/ethiopia, http://idpuk.org/OurProjects/Agriculture/Rural\%20poverty\%20in\%20Ethiopia.pdf.

4. Alderman $\mathrm{H}$. Safety nets can help address the risks to nutrition from increasing climate variability. J Nutr. 2010;140(1):148S-52S.

5. Berhane G, Hoddinott JF, Kumar N. The impact of Ethiopia'sProductive safety nets and household asset building Programme: 2006-2010; 2012.

6. Devereux $\mathrm{S}$, et al. Ethiopia's productive safety net programme: trends in PSNP transfers within targeted households. Brighton: Institute of Development Studies; 2006.

7. Gilligan DO, Hoddinott J, Taffesse AS. The impact of Ethiopia's productive safety net Programme and its linkages. J Dev Stud. 2009;45(10):1684-706.

8. Central Statistical Agency [Ethiopia] and ICF International. Ethiopia Demographic and Health Survey 2016. Addis Ababa, and Calverton: Central Statistical Agency and ORC Macro; 2016.

9. CSA. Ethiopia Demographic and Health Survey. Addis Ababa and Calverton: Central Statistics Agency and ORC Macro; 2011.

10. CSA. Ethiopia Mini Demographic and Health Survey. Adiss Ababa: CSA\&MOH; 2014.

11. Devereux S. Food insecurity in Ethiopia: A discussion paper for DFID. Institute for Development Studies, University of Sussex, UK; 2000. p. 7.

12. Central Statistical Agency [Ethiopia] and ICF International. Ethiopia Min Demographic and Health Survey 2011. Addis Ababa and Calverton: Central Statistical Agency and ORC Macro; 2011

13. Rodamo KM, Fiche YA, Geleto FB, Abebe RF, Dangiso DD. Magnitude and Associated Factors of Protein Energy Malnutrition among Children Aged 659 Months in Wondogenet District, Sidama Zone, Southern Ethiopia. J Gynecol Obstetr. 2018;6(3):47-55.

14. Golden $M H$, Grellety $Y$. Guidelines for the integrated management of severe acute malnutrition: in-and out-patient treatment. Paris: ACF International; 2011.

15. Belachew T, et al. Food insecurity, school absenteeism and educational attainment of adolescents in Jimma zone Southwest Ethiopia: a longitudinal study. Nutr J. 2011;10:29.

16. Coll-Black S. Ethiopia-ET Productive Safety Nets Project 4 (PSNP 4): P146883Implementation Status Results Report: Sequence 03. Washington, D.C: The World Bank; 2016

17. Rodamo, K.M., et al., Magnitude and associated factors of protein energy malnutrition among children aged 6-59 months in Wondogenet District, Sidama zone, Southern Ethiopia 2018. 6(3): p. 47-55.

18. Organization WH. WHO child growth standards: length/height for age, weight-for-age, weight-for-length, weight-for-height and body mass indexfor-age, methods and development. Geneva: World Health Organization; 2006

19. Devereux S, et al. Trends in PSNP transfers within targeted households. Addis Ababa: Institute of Development Studies, Sussex and Indak International; 2006.

20. Hoddinott J, et al. The impact of Ethiopia's productive safety net Programme and related transfers on agricultural productivity. J Afr Econ. 2012;21(5):761-86.

21. FAO and FHI 360. Minimum Dietary Diversity for Women: A Guide for Measurement. Rome: FAO; 2016.

22. Haile D, et al. Exploring spatial variations and factors associated with childhood stunting in Ethiopia: spatial and multilevel analysis. BMC Pediatr. 2016;16:49.

23. Mihrete $Y$. Assessment of Stuntng, Wastng Rate and Associated Factors among Children 0-59 Months at Jigjiga Town in Somali Regional State, Ethiopia. J Food Nutr Popul Health. 2018;2(3):1-4.

24. Fotso J-C, Kuate-Defo B. Measuring socioeconomic status in health research in developing countries: should we be focusing on households, communities or both? Soc Indic Res. 2005;72(2):189-237.

25. Gwatkin DR, et al. Socio-economic differences in health, nutrition, and population within developing countries. Washington, DC: World Bank; 2007. p. 287. 
26. Houweling TA, Kunst AE, Mackenbach JP. Measuring health inequality among children in developing countries: does the choice of the indicator of economic status matter? Int J Equity Health. 2003;2:8.

27. Mohsena M, Mascie-Taylor CG, Goto R. Association between socio-economic status and childhood undernutrition in Bangladesh; a comparison of possession score and poverty index. Public Health Nutr. 2010;13:1498-504.

28. Rohner F, et al. Comparison of a possession score and a poverty index in predicting anaemia and undernutrition in pre-school children and women of reproductive age in rural and urban cote d'Ivoire. Public Health Nutr. 2012;15(9):1620-9.

29. Adugnga T, et al. Assessment of nutritional status and associated factors of children under 5years of age in Dabat town, North Gondar. Ethiopia. 2017; 20(2):84-96.

30. Habaasa G. Determinants of malnutrition among under-five children in Nakaseke And Nakasongola Districts, Uganda (Doctoral dissertation, Makerere University); 2014.

31. Assefa H, Belachew T, Negash L. Socio-demographic factors associated with underweight and stunting among adolescents in Ethiopia. Pan Afr Med J. 2015;20:252.

32. Haile A, Amboma TA. Children's nutritional status and its determinants in small towns, Sebeta Hawas district, Oromia, Ethiopia. Int J Food Sci Nutr. 2018:1(1):33-47.

33. Abdulahi A, et al. Nutritional status of under five children in Ethiopia: a systematic review and meta-analysis. Ethiop J Health Sci. 2017;27(2):175-88.

\section{Publisher's Note}

Springer Nature remains neutral with regard to jurisdictional claims in published maps and institutional affiliations.

Ready to submit your research? Choose BMC and benefit from:

- fast, convenient online submission

- thorough peer review by experienced researchers in your field

- rapid publication on acceptance

- support for research data, including large and complex data types

- gold Open Access which fosters wider collaboration and increased citations

- maximum visibility for your research: over $100 \mathrm{M}$ website views per year

At BMC, research is always in progress.

Learn more biomedcentral.com/submissions 